\title{
APLIKASI CAMPURAN ALGINAT DARI Sargassum crassifolium DAN GUM SEBAGAI PENGENTAL TEXTILE PRINTING
}

\section{Applications of the Mixture of Alginate from Sargassum crassifolium with Gum as a Textile Printing Thickener}

\author{
Subaryono ${ }^{1 *}$, Tazwir ${ }^{1}$, Amir Husni ${ }^{2}$, Ustadi ${ }^{2}$, dan Yudi Pranoto ${ }^{3}$ \\ ${ }^{1}$ Balai Besar Penelitian dan Pengembangan Pengolahan Produk dan Bioteknologi Kelautan dan Perikanan, \\ JI. K.S. Tubun Petamburan VI, Jakarta Pusat, Indonesia \\ 2 Jurusan Perikanan Fakultas Pertanian UGM, Yogyakarta, Indonesia \\ ${ }^{3}$ Fakultas Teknologi Pertanian UGM, Yogyakarta, Indonesia \\ * Korespondensi Penulis: yono_ipn@yahoo.co.id
}

Diterima: 10 Juli 2015; Disetujui: 12 Oktober 2015

\begin{abstract}
ABSTRAK
Penelitian aplikasi campuran alginat dari Sargassum crassifolium dan gum untuk meningkatkan viskositas alginat sebagai pengental pada textile printing telah dilakukan. Viskositas campuran alginat dengan guar gum, gum arab, dan locust bean gum diamati pada penyimpanan selama 8 jam. Produk terbaik diujikan sebagai pengental pada textile printing. Campuran alginat dengan guar gum pada perbandingan 90:10 dan 80:20 meningkatkan viskositas dan stabilitas alginat selama penyimpanan. Campuran alginat dengan gum arab dan locust bean gum akan menurunkan viskositas alginat sehingga tidak sesuai untuk aplikasi textile printing. Aplikasi campuran alginat dengan guar gum 90:10 dan 80:20 sebagai pengental pada tekstil printing menghasilkan produk akhir yang setara dengan pengental komersial manutex.
\end{abstract}

KATA KUNCl: $\quad$ alginat, guar gum, locust bean gum, gum arab, textile printing

\section{ABSTRACT}

Research on applications of the mixture of alginate from Sargassum crassifolium with various gum to increase alginate viscosity as a thickener in textile printing has been carried out. Viscosity of the mixture of alginate with guar gum, locust bean gum and arabic gum was observed during 8 hours storage. The best product was tested as a thickener in textile printing. The mixture of alginate with guar gum on the ratio of 90:10 and 80:20 increased the viscosity and stability of alginate during storage. The mixture of alginate with arabic gum and locust bean gum reduced the viscosity of alginate, therefore it was not suitable for textile printing applications. Applications of the mixture of alginate with guar gum on the ratio of 90:10 and 80:20 as a thickener in textile printing produced a final product that was equivalent to a commercial thickener manutex.

KEYWORDS: $\quad$ alginate, guar gum, locust bean gum, arabic gum, textile printing

\section{PENDAHULUAN}

Rumput laut coklat Sargassum sp. merupakan salah satu jenis rumput penghasil alginat seperti banyak ditemukan di Perairan Indonesia yang tersebar dari perairan Pulau Anambas hingga Perairan Maluku dan Papua (Kadi, 2009 dalam Subaryono, 2011). Meskipun sumberdaya rumput laut coklat ini melimpah, tetapi pemanfaatannya sampai saat ini belum optimal. Pemanfaatan yang paling banyak dari rumput laut ini adalah dipasarkan dalam bentuk rumput laut kering, yang banyak diminati pasar dunia seperti
China dan Malaysia (Subaryono, 2011). Teknologi ekstraksi alginat dari rumput laut coklat ini juga sudah dikuasai (Husni et al., 2012).

Alginat banyak dimanfaatkan sebagai bahan pengental seperti pada industri textile printing. Aplikasi alginat dari rumput laut lokal Sargassum filipendula sebagai pengental pada pencapan batik sudah pernah dilakukan dan menghasilkan produk akhir yang baik (Sinurat \& Murdinah, 2007). Meskipun demikian, pada umumnya alginat dari rumput laut Sargassum sp. memiliki viskositas yang rendah, sehingga dalam 
penggunaannya sebagai pengental memerlukan konsentrasi yang lebih tinggi (Subaryono \& Peranginangin, 2009).

Adanya kelemahan penggunaan alginat sebagai pengental pada textile printing karena viskositasnya yang rendah, stabilitasnya yang kurang baik maupun kecenderungan terjadinya pengendapan pada larutan dengan kandungan ion yang tinggi, medorong beberapa peneliti mencoba mencari alternatif pengental dari pati atau selulosa yang termodifikasi (Abdel-Halim et al., 2008; Tatongjai \& Lumdubwong, 2010; Zhang et al., 2012), melakukan formulasi dari pengental sintetik (Ibrahim et al., 1994), menggunakan aplikasi surfactan (Fijan et al., 2007) atau mendaur ulang pengental yang sudah dipakai (Fijan et al., 2009). Gum sendiri seperti guar gum juga memiliki potensi digunakan sebagai pengental pada textile printing (Turk \& Schneider 1998).

Kombinasi alginat dengan gum seperti locust bean gum terbukti dapat meningkatkan viskositas alginat yang masih rendah (Subaryono \& Peranginangin, 2009). Oleh karena itu perlu dicoba formulasi antar berbagai jenis gum dengan alginat untuk mendapatkan sifat pengental textile printing yang lebih baik. Dalam penelitian ini akan dicoba formulasi alginat dengan beberapa jenis gum yang diketahui memiliki interaksi dengan alginat, sehingga diharapkan dapat memperbaiki viskositasnya. Pencampuran ini diharapkan dapat meningkatkan viskositas alginat yang masih rendah sehingga dapat diaplikasikan sebagai pengental pada textile printing.

\section{BAHAN DAN METODE}

\section{Bahan}

Natrium alginat yang digunakan dalam penelitian diekstrak dari rumput laut Sargassum crassifolium dengan metode jalur asam yang dimodifikasi (Husni et al., 2012). Guar gum, gum arab, dan locust bean gum diperoleh dari Sigma-Aldrich Jerman. Manutex yang merupakan pengental komersial diperoleh dari Industri textile printing di Solo, digunakan sebagai standar komerisal utuk pengujian.

\section{Metode}

\section{Pencampuran alginat dan gum}

Pencampuran alginat dengan guar gum, alginat dengan gum arab dan alginat dengan locust bean gum masing-masing dengan perbandingan 90:10, 80:20, dan 70:30 (w/w). Besarnya proporsi alginat dan gum ini didasarkan pada hasil penelitian sebelumnya yang menunjukkan bahwa penambahan gum (locust bean gum) sebanyak $30 \%$ dari alginat disertai dengan keberadaan ion $\mathrm{Ca}^{++}$sudah dapat meningkatkan viskositas campuran sekitar dua kali lipat yaitu dari $275 \mathrm{cP}$ menjadi $556 \mathrm{cP}$ (Subaryono \& Peranginangin, 2009). Penambahan gum dengan jumlah maksimal $30 \%$ dimaksudkan untuk meningkatkan pemanfaatan alginat yang diekstraksi dari rumput laut lokal dan mengurangi ketergantungan produk impor. Selama ini gum tersebut masih merupakan produk impor dengan harga yang relatif mahal. Selain itu, penambahan gum dalam jumlah yang besar juga beresiko menyebabkan terbentuknya gel, yang dapat mengganggu dalam proses printing. Sebagai kontrol digunakan pengental manutex dan alginat tanpa campuran gum.

Viskositas hidrokoloid diukur pada konsentrasi 1\% (b/v) dengan brookfield viscometer. Untuk melihat perubahan viskositas selama penyimpanan, pengukuran viskositas dilakukan pada jam ke-0, 2, 4, 6, dan 8. Lama waktu penyimpanan ini didasarkan pada aplikasi alginat sebagai pengental textile printing yang umumnya dilakukan untuk satu hari kerja atau 8 jam. Penelitian dilakukan dengan tiga kali ulangan.

\section{Aplikasi campuran alginat dan gum sebagai pengental textil printing}

Formula terbaik yaitu campuran yang menghasilkan viskositas yang cukup tinggi mendekati standar manutex, tidak menunjukkan penurunan viskositas selama penyimpanan serta memiliki stabilitas yang baik (tidak membentuk gel pada akhir penyimpanan) yang dipilih sebagai pengental textile printing. Sebagai kontrol digunakan standar manutex serta alginat komersial produksi Korea yang akhirakhir ini banyak digunakan industri textile printing karena harganya yang murah. Pengujian dilakukan pada konsentrasi yang menghasilkan kekentalan larutan induk yang cukup tinggi yaitu sekitar 10000 cP. Pewarna yang digunakan adalah dari kelompok reaktif dyes. Kondisi uji coba aplikasi textile printing adalah: konsentrasi pengental $30-55 \mathrm{~g} / 1000 \mathrm{ml}$ air, sodium bicarbonat $40 \mathrm{~g} / 1000 \mathrm{ml}$ air, Be $40-50$, colour distuf (Blue $\mathrm{P} \times 2 \mathrm{R}=40$ ), suhu fiksasi/steam $85^{\circ} \mathrm{C}$ selama 15 menit.

Kualitas produk textile printing yang diamati adalah ketajaman motif (Amirudin, 1987), kekakuan total (BSN, 1998b), ketahanan terhadap pencucian (BSN, 1998a), ketahanan terhadap gosokan (BSN, 1989) dan uji beda warna $(\triangle E)$ (Amirudin, 1987). Persentase ketajaman motif diukur sebagai $\mathrm{A} / 19 \times 100 \%$, di mana A adalah panjang motif hasil pencapan (Amirudin, 1987). Uji aplikasi textile printing dilakukan di Balai Besar Penelitian dan Pengembangan Industri Batik Bandung. Penelitian dilakukan dengan tiga kali ulangan. 


\section{HASIL DAN BAHASAN}

\section{Formulasi Alginat dan Gum}

Hasil pengamatan viskositas campuran alginatgum disajikan pada Tabel 1. Dari data tersebut terlihat bahwa viskositas awal alginat hasil ekstraksi dari Sargassum crassifolium ini sekitar $170 \mathrm{cP}$ lebih rendah dibandingkan manutex sebesar 396,33 cP. Viskositas alginat yang rendah ini kemungkinan disebabkan karena umur rumput laut yang masih muda sehingga polimer alginat yang terkandung di dalamnya masih memiliki berat molekul yang rendah. Viskositas alginat ini jauh lebih rendah dari hasil penelitian Mahmood \& Siddique (2010) untuk alginat dari rumput laut Sargassum terrarium yang diberi perlakuan penambahan $0,1 \% \mathrm{CuCl}_{2}$ yang pada umumnya menghasilkan viskositas larutan pada berbagai suhu $>1000 \mathrm{cP}$.

Formulasi alginat dengan gum menunjukkan pengaruh yang nyata $(p<0,01)$ khususnya terhadap peningkatan viskositasnya. Campuran alginat dengan gum arab maupun locust bean gum cenderung menurunkan viskositas larutan sehingga lebih rendah dibandingkan viskositas alginat awal. Hal ini terkait juga dengan rendahnya viskositas kedua jenis gum ini. Viskositas locust bean gum ini dilaporkan cukup rendah yaitu $56 \mathrm{cP}$ pada konsentrasi $0,5 \%$ (Subaryono \& Peranginangin, 2009). Viskositas gum arab juga dilaporkan rendah yaitu antara 55,6-81,1 cP tergantung pada kondisi tanah dan curah hujan tempat tanaman ini tumbuh (Amin et al., 2013). Sebaliknya, formulasi alginat dengan guar gum terlihat nyata meningkatkan viskositas larutan. Campuran alginat dengan guar gum 90:10 dan 80:20 selama penyimpanan memiliki viskositas yang mendekati namun tidak lebih rendah dari produk komersial manutex, sehingga terpilih untuk pengujian aplikasi pada textile printing. Campuran alginat dengan guar gum $30 \%$ menghasilkan viskositas yang terlalu tinggi dan pada akhir penyimpanan terjadi pembentukan gel sehingga tidak dipilih untuk aplikasi pengental textile printing. Hal ini sesuai dengan penelitian Dong-Bao

Tabel 1. Viskositas campuran alginat dengan berbagai gum dan stabilitasnya selama penyimpanan untuk textile printing $(\mathrm{cP})$

Table 1. Viscosity of the mixture of alginate with various gums and its stability during storage for textile printing $(C P)$

\begin{tabular}{|c|c|c|c|c|c|}
\hline \multirow{2}{*}{ Formulasi/Formulation } & \multicolumn{5}{|c|}{ Waktu Pengamatan (jam)/Accesing Time (hours) } \\
\hline & 0 & 2 & 4 & 6 & 8 \\
\hline Manutex & $396.3 \pm 7.2$ & $439.7 \pm 6.8$ & $420.7 \pm 2.5$ & $442.0 \pm 4.0$ & $425.7 \pm 6.4$ \\
\hline Alginat/Alginate & $170.0 \pm 2.9$ & $172.3 \pm 5.1$ & $170.0 \pm 5.2$ & $192.0 \pm 3.5$ & $186.0 \pm 3.5$ \\
\hline $\begin{array}{l}\text { Alginat-gum arab/ } \\
\text { Alginate-arabic gum 90:10 }\end{array}$ & $156.0 \pm 11.9$ & $152.7 \pm 8.1$ & $141.0 \pm 2.6$ & $165.3 \pm 4.5$ & $178.67 \pm 7.0$ \\
\hline $\begin{array}{l}\text { Alginat-gum arab/ } \\
\text { Alginate-arabic gum } 80: 20\end{array}$ & $132.0 \pm 3.6$ & $129.7 \pm 10.7$ & $115.7 \pm 2.5$ & $135.3 \pm 0.6$ & $159.3 \pm 5.0$ \\
\hline $\begin{array}{l}\text { Alginat-gum arab/ } \\
\text { Alginate-arabic gum } 70: 30\end{array}$ & $111.0 \pm 7.0$ & $113.3 \pm 6.5$ & $104.7 \pm 5.9$ & $136.7 \pm 5.1$ & $141.0 \pm 8.0$ \\
\hline $\begin{array}{l}\text { Alginat-guar gum/ } \\
\text { Alginate-guar gum 90:10 }\end{array}$ & $231.3 \pm 18.0$ & $293.3 \pm 4.7$ & $313.0 \pm 2.0$ & $344.0 \pm 7.2$ & $348.3 \pm 7.1$ \\
\hline $\begin{array}{l}\text { Alginat-guar gum/ } \\
\text { Alginate-guar gum 80:20 }\end{array}$ & $378.3 \pm 18.0$ & $618.3 \pm 2.1$ & $659.0 \pm 5.6$ & $679.7 \pm 3.5$ & $684.3 \pm 3.8$ \\
\hline $\begin{array}{l}\text { Alginat-guar gum/ } \\
\text { Alginate-guar gum 70:30 }\end{array}$ & $478.7 \pm 13.9$ & $761.7 \pm 3.1$ & $854.7 \pm 10.2$ & $883.7 \pm 4.7$ & $746.0 \pm 18.4$ \\
\hline $\begin{array}{l}\text { Alginat-locust bean gum/ } \\
\text { Alginate-locust bean gum 90:10 }\end{array}$ & $149.7 \pm 3.5$ & $209.0 \pm 2.6$ & $223.3 \pm 3.8$ & $252.7 \pm 6.1$ & $232.0 \pm 11.5$ \\
\hline $\begin{array}{l}\text { Alginat-locust bean gum/ } \\
\text { Alginate-locust bean gum 80:20 }\end{array}$ & $151.7 \pm 2.1$ & $248.3 \pm 7.6$ & $276.3 \pm 5.1$ & $302.3 \pm 5.5$ & $290.7 \pm 3.8$ \\
\hline $\begin{array}{l}\text { Alginat-locust bean gum/ } \\
\text { Alginate-locust bean gum 70:30 }\end{array}$ & $156.3 \pm 4.04$ & $241.3 \pm 9.1$ & $266.0 \pm 00$ & $296.0 \pm 3.0$ & $286.3 \pm 7.5$ \\
\hline
\end{tabular}

Keterangan/Note: Nilai dari rerata 3 kali ulangan dan standar deviasinya/

Value of tree times replication and its standard deviation 
et al. (2004), yang menyatakan bahwa interaksi sinergistik antara guar gum dengan alginat dapat terjadi dan meningkatkan kemampuan membentuk gel dari campuran tersebut. Kekuatan gel maksimum dilaporkan terjadi pada rasio antara guar gum dan natrium alginat 60:40. Viskositas guar gum sendiri pada konsentrasi $1 \%$ dan shear rate $50 \mathrm{~s}^{-1}$ dilaporkan sebesar 359 cP (Venugopal \& Abhilash, 2010). Menurut Turk dan Schneider (2000), guar gum sendiri juga dapat digunakan sebagai pengental pada printing, sehingga campurannya dengan alginat juga cukup baik dalam meningkatkan viskositas maupun stabilitasnya selama penyimpanan. Ragheb et al. (2006) juga berhasil meningkatkan viskositas alginat sebagai textile printing dengan penambahan Carboxymethyl Starch (CMS), sehingga penggunaannya sebagai pengental pada texttile printing semakin efisien.

Dari data tersebut terlihat pula bahwa campuran alginat dengan guar gum menghasilkan viskositas yang cenderung meningkat seiring peningkatan waktu penyimpanan. Hal ini kemungkinan disebabkan karena adanya interaksi dengan alginat, sehingga menghasilkan sifat viskositas yang berbeda dengan karakter viskositas asli dari masing-masing bahan. Guar gum yang bersifat kationik dilaporkan berinteraksi secara sinergistik dengan alginat yang cenderung bermuatan negatif (Dong-Bao et al., 2004). Sifat viskositas guar gum sendiri dilaporkan turun seiring lamanya waktu penyimpanan, yang diduga karena adanya degradasi enzimatik (El-Daw, 1998). Pada campuran alginat dengan guar gum 70:30, viskositas yang dihasilkan terlalu tinggi dibandingkan standar komersial, dan pada akhir penyimpanan sebagian larutan sudah membentuk gel. Oleh karena itu penggunaan formulasi alginat dengan guar gum sebagai pengental pada textile printing pada perbandingan ini tidak sesuai karena terbentuknya gel akan mengganggu pada proses pencetakan.

\section{Aplikasi Campuran Terbaik sebagai Pengental pada Textile Printing}

Secara umum viskositas campuran alginat guar gum 90:10 (B) dan 80:20 (C) mendekati atau lebih tinggi dari pengental komersial manutex $(A)$ dan lebih tinggi pula dibandingkan alginat komersial Korea (D). Meskipun viskositas campuran ini cukup tinggi tetapi pada akhir penyimpanan tidak menunjukkan terbentuknya gel yang dapat mengganggu aplikasinya pada textile printing (Tabel 1). Oleh karena itu kedua campuran ini dipilih untuk uji aplikasi pada textile printing.

Hasil pengamatan produk textile printing disajikan pada Gambar 1. Uji ketajaman motif menunjukkan bahwa campuran alginat dan guar gum 90:10 dan 80:20 menghasilkan ketajaman motif yang setara dengan standar manutex sebesar $100 \%$. Ketajaman motif alginat komersial Korea dilaporkan 100,51\% yang menunjukkan nilai yang tidak baik karena hasil printing lebih panjang dibandingkan pencetaknya. Nilai ketajaman motif hasil penelitian ini lebih baik dibandingkan dengan penelitian Sinurat \& Murdinah (2007) yang menggunakan alginat dari rumput laut Sargassum filipendula dan menghasilkan ketajaman motif antara 102,2-102,9\%. Nilai ideal ketajaman motif adalah $100 \%$ yang artinya produk hasil printing sama dengan pola yang digunakan pada pencetakan. Ketajaman motif erat kaitannya dengan viskositas larutan printing yang digunakan. Jika viskositas larutan ini rendah maka kecenderungan untuk menghasilkan printing yang melebar dari pencetaknya akan semakin besar (Kuntari, 2007). Dari data viskositas terlihat bahwa perbedaan viskositas antara manutex, campuran alginat:guar gum 90:10 dan campuran alginat:guar gum 80:20 tidak terlalu besar, yaitu berada pada kisaran 231-396 cP dan ini menghasilkan nilai ketajaman motif yang sama yaitu $100 \%$

Uji kekakuan kain menunjukkan bahwa perlakuan campuran alginat:guar gum 90:10 memberikan nilai kekakuan 66,43 mg.cm dan campuran alginat:guar gum 80:20 sebesar 71,73 mg.cm. Kekakuan kain standar manutex (A) lebih rendah sebesar 63,78 mg.cm dan alginat komersial Korea 55,86 mg.cm. Nilai kekakuan kain campuran alginat:guar gum 90:10 ini tidak berbeda nyata dengan produk komersial Manutex, tetapi jika dibandingkan produk Korea masih lebih tinggi. Meskipun demikian hasil penelitian ini menghasilkan kekakuan kain yang lebih baik dibandingkan dengan penelitian Sinurat dan Murdinah (2007) yang menggunakan alginat dari rumput laut Sargassum filipendula dan menghasilkan kekauan kain antara 67,61 dan 93,71 mg.cm. Semakin tinggi nilai kekakuan kain menunjukkan mutu kain yang semakin kurang baik (Djufri 1976 dalam Sinurat \& Murdinah, 2007).

Dari data tersebut terlihat bahwa kekakuan kain meningkat dengan meningkatknya proporsi penambahan guar gum, yang terlihat dari meningkatkan kekauan kain pada campuran 80:20 dibandingkan campuran 90:10 dan tanpa campuran guar gum (manutex dan alginat Korea). Menurut Kuntari (2007), kekakuan kain sangat ditentukan oleh jenis binder yang digunakan pada textile printing, suhu serta waktu proses pemanasan sediaan. Pada penelitian ini proses pemanasan dilakukan seragam pada suhu fiksasi/steam $85^{\circ} \mathrm{C}$ selama 15 menit, sehingga kekakuan kain yang terjadi merupakan hasil pengaruh jenis binder yang digunakan. Polimer binder 

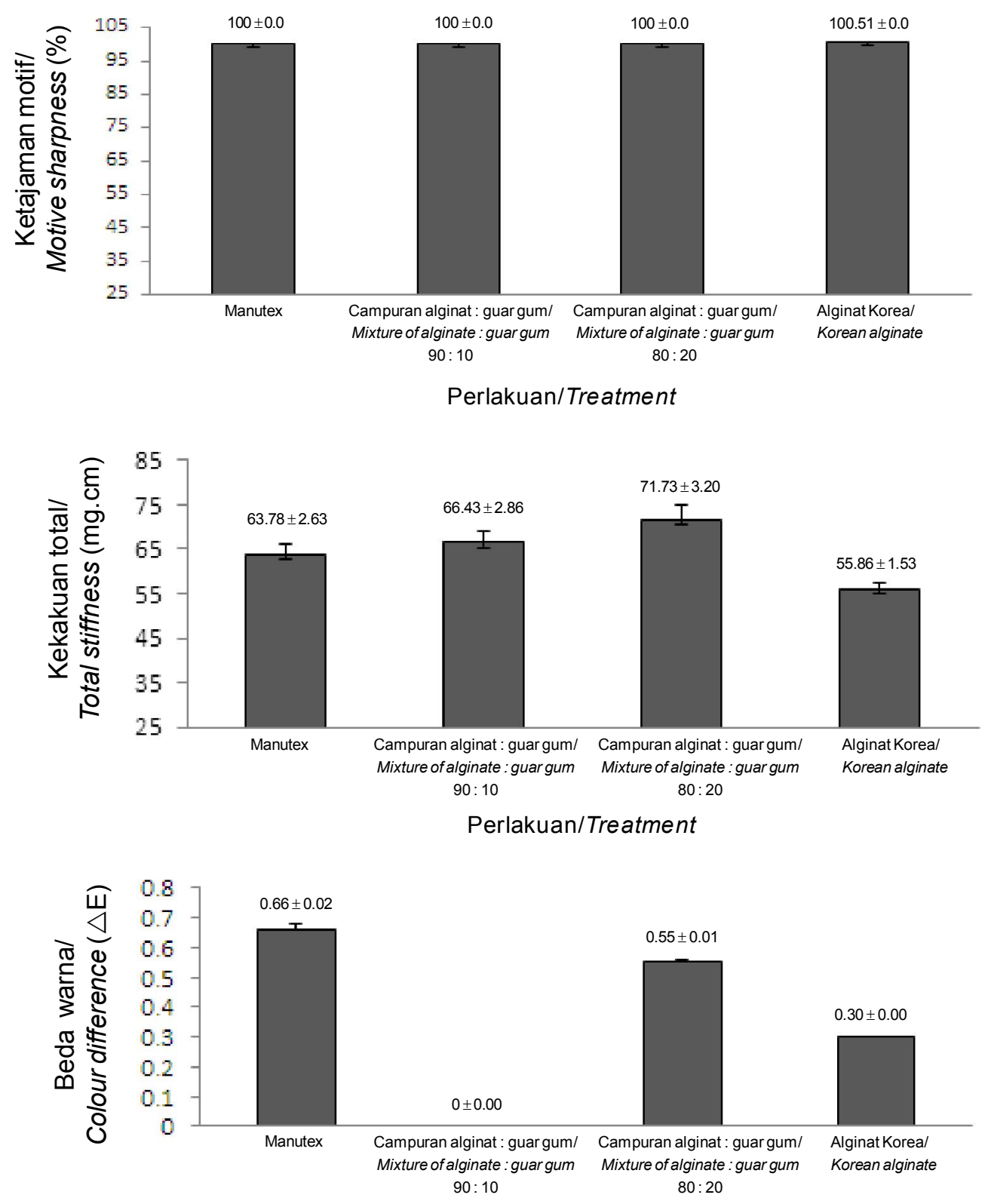

Perlakuan/Treatment

Gambar 1. Nilai ketajaman motif, kekakuan total dan beda warna produk printing dari formula terpilih.

Figure 1. Value of motive sharpnes, total stiffness and colour difference of printing product from selected formula.

bersifat melemaskan, sehingga makin tinggi kualitas binder sifat fleksibilitas binder semakin baik, dan binder tersebut akan membuat ikatan tiga dimensi antara zat warna, serat dan polimer binder yang membentuk film tipis yang fleksibel/tidak kaku (Kuntari, 2007). Alginat merupakan polimer yang bersifat kental dan menghasilkan fleksibilitas yang baik pada kain. Meskipun demikian, interaksinya dengan guar gum dapat meningkatkan kemampuan campuran ini membentuk gel (meningkatkan daya gelasi) dan menurunkan sifat fleksibilitasnya (DongBao et al., 2004). Hal ini terlihat dari meningkatnya nilai kekakuan kain dengan meningkatnya proporsi guar gum yang ditambahkan. Menurut Dong-Bao et al. (2004), daya gelasi campuran guar gum dan alginat maksimum terjadi pada proporsi 60:40.

Hasil uji beda warna juga menunjukkan bahwa perbedaan warna antar perlakuan cukup kecil yaitu berkisar antara $0,30-0,66$. Formula alginat:guar gum 90:10 menghasilkan nilai beda warna 0,0 sedangkan 
Tabel 2. Uji ketahanan terhadap pencucian dan gosokan produk textile printing dari formula terpilih Table 2. Resistance to washing and ironing test of textile printing product from selected formula

\begin{tabular}{lcc}
\hline \multicolumn{1}{c}{ Pengental/Thickener } & $\begin{array}{c}\text { Ketahanan terhadap } \\
\text { Pencucian/ } \\
\text { Resistance to Washing }\end{array}$ & $\begin{array}{c}\text { Ketahanan terhadap } \\
\text { Gosokan/ } \\
\text { Resistance to Ironing }\end{array}$ \\
\hline Manutex/Manutex & $4-5 \pm 0.0$ & $4-5 \pm 0.0$ \\
Alginat:guar gum/Alginate:guar gum 90:10 & $4-5 \pm 0.0$ & $4-5 \pm 0.0$ \\
Alginat:guar gum/Alginate:guar gum 80:20 & $4-5 \pm 0.0$ & $4-5 \pm 0.0$ \\
Alginat Korea/Korean alginate & $4-5 \pm 0.0$ & $4-5 \pm 0.0$ \\
\hline
\end{tabular}

Keterangan/Note: Nilai dari rerata 3 kali ulangan dan standar deviasinya/ Value of tree times replication and its standard deviation

formula 80:20 memiliki nilai yang berada di antara produk komersial manutex 0,66 dan alginat Korea 0,3. Semakin rendah nilai beda warna menunjukkan mutu yang semakin baik karena berarti antar perlakuan memiliki keseragaman yang tinggi. Dari penelitian ini perlakuan formula alginat:guar gum 90:10 menghasilkan nilai beda warna 0 atau tidak ada beda warna, sedangkan formula alginat:guar gum 80:20 menghasilkan beda warna yang masih lebih baik dibandingkan produk komersial manutex.

Hasil pengamatan terhadap uji ketahanan produk textile printing terhadap pencucian dan terhadap gosokan ditampilkan pada Tabel 2. Uji ketahanan produk textile printing terhadap pencucian dan terhadap gosokan menunjukkan nilai yang seragam untuk semua perlakuan yaitu antara 4-5. Parameter ketahanan terhadap pencucian dan gosokan memiliki rentang nilai dari $1-5$ (nilai 1 sangat tidak bak, nilai 5 sangat baik). Dengan demikian maka aplikasi formula ini menghasilkan ketahanan produk terhadap pencucian maupun gosokan yang sudah sangat baik dan memenuhi persyaratan. Nilai ini juga relatif sama dengan hasil penelitian Sinurat dan Murdinah (2007) yang menghasilkan nilai ketahanan terhadap pencucian dan gosokan sebesar 4,5. Menurut Kuntari (2007), ketahanan luntur warna pada zat warna sangat tergantung dari hasil polimerisasi dari polimer bindernya. Zat warna tidak bereaksi dengan serat, tetapi zat warna tersebut melekat dan melapisi kain karena adanya polimerisasi yang membentuk film jaringan tiga dimensi antara zat warna, serat dan polimerisasi antar polimer binder. Semakin baik polimerisasi binder yang digunakan maka akan menghasilkan ketahanan warna terhadap gosokan dan pencucian yang semakin baik (Kuntari, 2007). Dalam penelitian ini dapat diasumsikan bahwa polimerisasi alginat dan guar gum yang menjadi binder sudah cukup baik sehingga hasil uji ketahanan produk textile printing terhadap pencucian dan gosokan sudah sangat baik.
Dengan perbaikan viskositas alginat dan stabilitasnya selama penyimpanan ini maka potensi pemanfaatan alginat dari rumput laut Sargassum sp. yang umumnya viskositasnya rendah semakin besar. Selama ini rumput laut Sargassum sp. masih diekspor dalam kondisi rumput laut kering, sehingga nilai tambahnya masih rendah. Ekstraksi alginat dari rumput laut ini untuk memenuhi kebutuhan dalam negeri sangat memungkinkan mengingat potensi produksi rumput laut ini cukup tinggi. Selain itu meningkatnya kesadaran penggunaan bahan pengental textile printing yang ramah lingkungan juga mendorong penggunaan bahan alam yang lebih tinggi dibandingkan bahan-bahan pengental sintetis (Turk \& Schneider, 1998).

\section{KESIMPULAN}

Hasil penelitian menunjukkan bahwa campuran alginat dengan guar gum pada perbandingan 90:10 dan 80:20 (w/w) menghasilkan perbaikan viskositas campuran dan stabilitasnya selama penyimpanan yang ditandai dengan tidak terbentuknya gel pada akhir masa penyimpanan. Campuran alginat dengan gum arab dan locust bean gum akan menurunkan viskositas alginat sehingga tidak sesuai untuk aplikasi textile printing.

Uji aplikasi campuran pengental pada tekstil printing menunjukkan bahwa campuran alginat dengan guar gum 90:10 dan 80:20 menghasilkan bahan pengental textile printing yang setara dengan pengental komersial Manutex. Jika dibandingkan dengan produk alginat komersial asal Korea, campuran alginat dan guar gum ini juga menghasilkan ketajaman motif yang lebih baik.

\section{SARAN}

Peluang pemanfaatan campuran alginat dengan guar gum sebagai pengental textile printing ini perlu 
dikaji lebih lanjut, khususnya dari perhitungan aspek ekonomi serta cara untuk menurunkan nilai kekakuan kainnya dengan variasi suhu dan waktu pemanasan yang tepat.

\section{DAFTAR PUSTAKA}

Abdel-Halim, E.S., Emam, H.E., \& El-Rafie, M.H. (2008). Utilization of hydroxypropyl cellulose and poly (acrylic acid)-hydroxypropyl cellulose composite as thickeners for textile printing. Carbohydrate Polymers, 74(4), 938-941.

Amin, E.E., Blal, M.E., \& Mahmoud, A.E. (2013). Gum Arabic (Acacia senegal (L.) Willd) viscosity in relation to rainfall and soil metal ions. Journal of Forest Products and Industries, 2(6), 34-37.

Amirudin. (1987). Pengujian pasta cap. Arena Tekstil No 5. Balai Besar Tekstil Bandung.

BSN. (1998a). Cara uji tahan luntur warna terhadap pencucian rumah tangga dan komersial. SNI 080285-1998. Badan Standarisasi Nasional.

BSN. (1998b). Cara uji kekakuan kain. SNI 08-03141998. Badan Standarisasi Nasional.

BSN. (1989). Cara uji tahan luntur warna terhadap gosokan. SNI 08-0288-1989. Badan Standarisasi Nasional.

Dong-Bao, H., Li-Hua, L., Qing, L., \& Xiao-Zhen, Y. (2004). Sinergistic interaction and gelation in cationic guar gum-sodium alginate system. Wuhan University Journal of Natural Sciences, 9(3), 371-374.

El-Daw, G.E. (1998). A study of guar seed and guar gum properties (Cyamopsis tetragonolabous). Thesis. Department of Food Science and Technology Faculty of Agriculture University of Khartoum.

Fijan, R., Basile, M., Šostar-Turk, S., Žagar, E., Žigon, M., \& Lapasin, R. (2009). A study of rheological and molecular weight properties of recycled polysaccharides used as thickeners in textile printing. Carbohydrate Polymers, 76(1), 8-16.

Fijan, R., Turk, S.S., \& Lapasin, R. (2007). Rheological study of interactions between non-ionic surfactants and polysaccharide thickeners used in textile printing. Carbohydrate Polymers, 68(4), 708-717.

Husni, A., Subaryono, Pranoto, Y., Tazwir, \& Ustadi. (2012). Pengembangan metode ekstraksi alginat dari rumput laut Sargassum sp. sebagai bahan pengental. Agritech, 32(1),1-8.

Ibrahim, N.A., El-Zairy, M.R., \& Abo-Shosha, M H. (1994). New synthetic thickeners for printing cotton with reactive dyes. Dyes and Pigments, 25(1), 1-13.

Kuntari. (2007). Penelitian pasta Emulsi Minasol M, Pertasol CA dan Pertasol CB pada Pencapan Kain Selulosa dengan Zat Warna Pigmen. Jurnal Sains Materi Indonesia, 8(2), 173-181.

Mahmood, S.J., \& Siddique, A. (2010). Ionic studies of sodium alginate isolated from Sargassum terrarium (brown algea) karachi coast with 2,1-electrolyte. Journal of Saudi Chemical Society, 14, 117-123.

Ragheb, A.A., El-Sayiad, H.S., \& Hebeish, A. (2006). Preparation and Characterization of Carboxymethyl Starch (CMS) Products and Their Utilization in Textile Printing. Starch, 49(6), 238-245.

Sinurat, E. \& Murdinah. (2007). Aplikasi alginat sebagai bahan pengental pada pencapan batik. Jurnal Pasca Panen dan Bioteknologi Kelautan dan Perikanan, 2(1), 1-8.

Subaryono (2011). Potensi dan Peluang Pemanfaatan Rumput Laut Coklat di Indonesia. Squalen, 6(2), 5562.

Subaryono \& Peranginangin, R. (2009). Perbaikan viskositas alginat dari Sargassum filipendula dan Turbinaria decurens menggunakan $\mathrm{CaCO} 3$ dan locust bean gum (LBG). Jurnal Pascapanen dan Bioteknologi Kelautan dan Perikanan, 4(2), 131-139.

Tatongjai, J. \& Lumdubwong, N. (2010). Physicochemical properties and textile utilization of low- and moderatesubstituted carboxymethyl rice starches wit. $\mathrm{h}$ various amylose content. Carbohydrate Polymers, 81(2), 377-384.

Turk, S.S., \& Schneider, R. (1998). Guar gum as an environment-friendly alternative Thickener in printing with reactive dyes. Dyes and Pigments, 39(4), 211221

Turk, S.S. \& Schneider, R. (2000). Printing properties of a high substituted guar gum and its mixture with alginate. Dyes and Pigments, 47(3), 269-275.

Zhang, B., Gong, H., Lü, S., Ni, B., Liu, M., Gao,C., Huang, Y., \& Han, F. (2012). Synthesis and characterization of carboxymethyl potato starch and its application in reactive dye printing. International Journal of Biological Macromolecules, 51(4), 668-674.

Venugopal, K.N. \& Abhilash, M. (2010). Study of Hydration Kinetics and Rheological Behaviour of Guar Gum. International Journal of Pharma Sciences and Research (IJPSR), 1(1), 28-39. 